\title{
Article \\ Structural and Optical Properties of Silicon Carbide Powders Synthesized from Organosilane Using High-Temperature High-Pressure Method
}

\author{
Evgeny A. Ekimov ${ }^{1}$, Vladimir S. Krivobok ${ }^{2, *}$, Mikhail V. Kondrin ${ }^{1} \oplus$, Dmitry A. Litvinov ${ }^{2}$, \\ Ludmila N. Grigoreva ${ }^{2,3}$, Aleksandra V. Koroleva ${ }^{3}$, Darya A. Zazymkina ${ }^{2}{ }^{\mathbb{D}}$, Roman A. Khmelnitskii ${ }^{2}$, \\ Denis F. Aminev ${ }^{2}$ and Sergey N. Nikolaev ${ }^{2}$ \\ 1 Institute for High Pressure Physics, Russian Academy of Sciences, Kaluzhskoe Shosse, 14, Troitsk, \\ 108840 Moscow, Russia; ekimov@hppi.troitsk.ru (E.A.E.); mkondrin@hppi.troitsk.ru (M.V.K.) \\ 2 P.N. Lebedev Physical Institute, Russian Academy of Sciences, Leninsky Prospect, 53, 119991 Moscow, Russia; \\ litvinovd@lebedev.ru (D.A.L.); ln.grigorjeva@physics.msu.ru (L.N.G.); zazymkina_darya@mail.ru (D.A.Z.); \\ roma@lebedev.ru (R.A.K.); amdenis@yandex.ru (D.F.A.); nikolaev-s@yandex.ru (S.N.N.) \\ 3 Faculty of Physics, Lomonosov Moscow State University, Leninskiye Gory 1, 119991 Moscow, Russia; \\ koroleva.phys@mail.ru \\ * Correspondence: kolob7040@gmail.com
}

check for updates

Citation: Ekimov, E.A.; Krivobok, V.S.; Kondrin, M.V.; Litvinov, D.A.; Grigoreva, L.N.; Koroleva, A.V.; Zazymkina, D.A.; Khmelnitskii, R.A.; Aminev, D.F.; Nikolaev, S.N. Structural and Optical Properties of Silicon Carbide Powders Synthesized from Organosilane Using HighTemperature High-Pressure Method. Nanomaterials 2021, 11, 3111. https:// doi.org/10.3390/nano11113111

Academic Editors: Sotirios Baskoutas and Baoquan Sun

Received: 11 October 2021

Accepted: 11 November 2021

Published: 18 November 2021

Publisher's Note: MDPI stays neutral with regard to jurisdictional claims in published maps and institutional affiliations.

Copyright: (c) 2021 by the authors. Licensee MDPI, Basel, Switzerland. This article is an open access article distributed under the terms and conditions of the Creative Commons Attribution (CC BY) license (https:// creativecommons.org/licenses/by/ $4.0 /)$.

\begin{abstract}
The development of new strategies for the mass synthesis of $\mathrm{SiC}$ nanocrystals with high structure perfection and narrow particle size distribution remains in demand for high-tech applications. In this work, the size-controllable synthesis of the SiC $3 C$ polytype, free of $\mathrm{sp}^{2}$ carbon, with high structure quality nanocrystals, was realized for the first time by the pyrolysis of organosilane $\mathrm{C}_{12} \mathrm{H}_{36} \mathrm{Si}_{6}$ at $8 \mathrm{GPa}$ and temperatures up to $2000{ }^{\circ} \mathrm{C}$. It is shown that the average particle size can be monotonically changed from $\sim 2 \mathrm{~nm}$ to $\sim 500 \mathrm{~nm}$ by increasing the synthesis temperature from $800{ }^{\circ} \mathrm{C}$ to $1400{ }^{\circ} \mathrm{C}$. At higher temperatures, further enlargement of the crystals is impeded, which is consistent with the recrystallization mechanism driven by a decrease in the surface energy of the particles. The optical properties investigated by IR transmission spectroscopy, Raman scattering, and low-temperature photoluminescence provided information about the concentration and distribution of carriers in nanoparticles, as well as the dominant type of internal point defects. It is shown that changing the growth modes in combination with heat treatment enables control over not only the average crystal size, but also the LO phonon-plasmon coupled modes in the crystals, which is of interest for applications related to IR photonics.
\end{abstract}

Keywords: crystal morphology; etching; growth models; nanostructures; X-ray diffraction; semiconducting silicon compounds

\section{Introduction}

Silicon carbide $(\mathrm{SiC})$ is the most widely used non-oxide ceramic, which has applications in many industrial fields, due to its special semiconducting and spin-related properties, high mechanical strength and hardness, high thermal conductivity, resistance to corrosion and thermal shock, etc. [1-12]. In modern literature, various SiC-based nanomaterials are also actively discussed in terms of their usage in manufacturing implantable microelectrodes, highly porous membranes [8], biosensors [8-12], micro- (MEMS) and nanoelectromechanical systems (NEMS) [5], and heat-resistant coatings [11]. A number of methods to synthesize nano- and micropowders have already been developed, including growth from hydrogen silicone oil [6], mechanical grinding [11,12], fast carbothermal synthesis [13-15], combustion synthesis [16], microwave synthesis [17], pyrolysis of polymers [18], sol-gel processes [19], CVD [20], and laser synthesis [21]. All of these processes have their own advantages and disadvantages, associated with the cost of precursors, synthesis conditions, the purity degree of the materials obtained, and others [7]. The problem 
of developing processes for the synthesis of nanosized $\mathrm{SiC}$, which has a high crystallinity degree, uniform particle size distribution, and is free of inclusions and structural defects, is still urgent [22]. In contrast to low-pressure synthesis paths [23,24], HPHT synthesis in the diamond stability region can ensure the formation of $\mathrm{SiC}$ nanopowders that are free of $\mathrm{sp}^{2}$ carbon. It is known that HPHT conditions are favorable for producing the $\mathrm{SiC} 3 \mathrm{C}$ polytype in the Si-C system [25,26], although its formation stability under pressure in the $\mathrm{C}-\mathrm{H}-\mathrm{Si}$ growth medium has not been investigated yet.

Special attention is paid to "core-shell" composite spherical nanostructures, which consist of a SiC core (inner material) and a shell (outer layer material). The latter can also consist of $\mathrm{SiC}$, but it can have different properties and show different behavior. Of particular interest is the situation in which either the core or the shell is characterized by a high free carrier concentration, which enables such particles to be considered as plasmon resonators for the mid-IR range [27]. It should also be noted that in polar $\mathrm{SiC}$ nanocrystals, localized phonon polaritons can exist along with localized surface plasmons [28,29]. In undoped nanocrystals, the excitation frequencies occupy the frequency range between the transverse and longitudinal lattice resonances [25]. The near fields of such excitations can also be of interest for the needs of IR photonics [30-32].

In this work, it is shown that synthesis from organosilanes at high pressures (HTHP) is one of the possible methods for obtaining nanopowders of $3 \mathrm{C}$ silicon carbide that are free of $\mathrm{sp}^{2}$ carbon, with high crystal quality and relatively low size dispersion. In this case, the synthesis temperature is the parameter that controls the particle size. The developed method also enables particles with well-defined phonon-plasmon resonance to be obtained, the structure of which can be tuned by heat treatment. This paper discusses the structural features of the synthesized powders, the composition of their background impurities, and the optical properties, with an emphasis on particles with pronounced phonon-plasmon resonance.

\section{Materials and Methods}

In this work nanosized and submicron $\mathrm{SiC}$ crystals were obtained by pyrolysis of an individual compound dodecamethylhexasilinane $\mathrm{C}_{12} \mathrm{H}_{36} \mathrm{Si}_{6}$ (organosilane), Sigma-Aldrich Chemie $\mathrm{GmbH}$, Taufkirchen, Germany, at high pressures and temperatures (Figure 1A). The choice of this compound for HPHT synthesis was due to its high purity ( $99.9 \%$ metal basis) and favorable chemical composition. On the one hand, dodecamethylhexasilinane contains excess carbon for silicon carbide formation, which can ensure the absence of unreacted silicon in the synthesis products. On the other hand, hydrogen is in excess in relation to carbon for methane formation, which should lead to the absence of free carbon in the growth medium. We used a toroid-type high-pressure cell for the synthesis at pressures of 8-9 GPa and temperatures up to $2000 \mathrm{~K}$. The heating elements of the cell consisted of graphite (graphite, MGOSCH 99.9999\%, NIIGrafit, Moscow, Russia) current leads and a titanium (99.99\%, Sigma-Aldrich Chemie GmbH, Taufkirchen, Germany) crucible heater (capsule), which were in contact with a chemically inert container made of refractory zirconium oxide (99.9\%, Sigma-Aldrich Chemie GmbH, Taufkirchen, Germany) [33]. The characteristic holding time at constant $\mathrm{P}$ and $\mathrm{T}$ was about 60 seconds. A uniaxial compression apparatus (homemade HPPI, Troitsk, Russia) and a high-pressure chamber of the "Toroid-15" type (homemade HPPI, Troitsk, Russia) created high pressures and temperatures. Dodecamethylhexasilinane tablets $(2.5-3 \mathrm{~mm}$ thick and $6 \mathrm{~mm}$ in diameter) were pressed and loaded into capsules in air. The graphite current leads were separated from the surface of the hard-alloy (WC $+\mathrm{Co}$ ) parts (homemade HPPI, Troitsk, Russia) of the high-pressure chamber by molybdenum ( $99.9 \%$ Sigma-Aldrich Chemie $\mathrm{GmbH}$, Taufkirchen Germany) disks $0.2 \mathrm{~mm}$ thick to prevent their interaction. The temperature in the experiment was determined by a chromel-alumel thermocouple (homemade HPPI, Troitsk, Russia) up to $1350{ }^{\circ} \mathrm{C}$. For higher synthesis temperatures, the temperature was estimated using a calibration dependence of the temperature in the reaction volume on the power of the electric current supplied for heating. The calibration dependence was previously found 
using a WRe 5/20 thermocouple (Contact of two wires: Wolfram 80\%-Renium 20\% wire and Wolfram 95\%-Renium 5\% wire). The titanium capsule started to interact with the contents of the cell, as well as the material of the container at temperatures exceeding $1300-1400{ }^{\circ} \mathrm{C}$. For this reason, a graphite capsule was also used for the synthesis in the temperature range $1700-2000{ }^{\circ} \mathrm{C}$. The mass of a sample obtained at temperatures above $800{ }^{\circ} \mathrm{C}$ was about $30-35 \mathrm{mg}$.
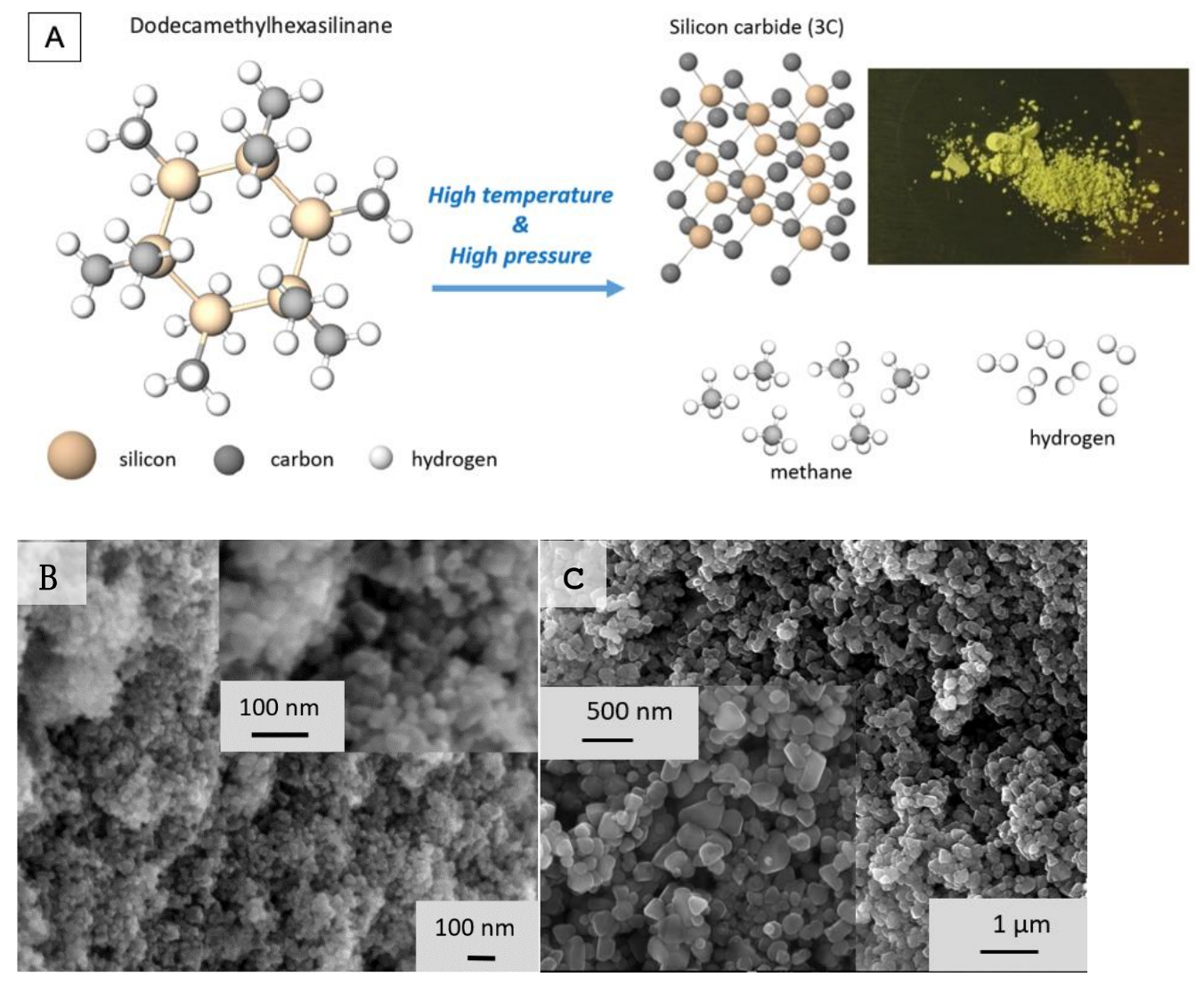

Figure 1. (A) The structure of dodecamethylhexasilinane $\left(\mathrm{C}_{12} \mathrm{H}_{36} \mathrm{Si}_{6}\right)$ molecule and scheme of $\mathrm{SiC}$ formation in HTHP reaction. Photos in the right part of (A) show an example of $3 \mathrm{C}$ SiC powders obtained at $2000^{\circ} \mathrm{C}$. $(\mathbf{B}, \mathrm{C}) \mathrm{SEM}$ images of $3 \mathrm{C} \mathrm{SiC}$ powders synthesized at temperatures of $1250^{\circ} \mathrm{C}$ and $1400{ }^{\circ} \mathrm{C}$, respectively.

The determination of the elemental sample composition, as well as the morphology study of the synthesis products, was carried out using a JEOL JSM-6390LV, JEOL Ltd. Tokyo, Japan, electron microscope equipped with EDX microanalysis. Except for oxygen, impurities were not detected by EDX analysis; their concentration was less than the detection limit of 0.1-0.05 wt. \% by the EDX method (see Figure S1 of Supplementary Materials). Quantitative atomic emission spectral analysis (ISP 30, ASMA-Pribor, Moscow, Russia) with use of standards shows presence of $\mathrm{Ca}\left(<10^{-3}\right.$ mass $\left.\%\right), \mathrm{Al}\left(<10^{-3}\right.$ mass $\left.\%\right), \mathrm{Fe}$ $\left(<10^{-3}\right.$ mass $\left.\%\right), \mathrm{Mg}\left(<10^{-3}\right.$ mass $\left.\%\right)$ and $\mathrm{B}\left(<10^{-3}\right.$ mass $\left.\%\right)$ in initial compound and samples obtained. X-ray diffraction studies $\left(\mathrm{Cu} \mathrm{K}_{\alpha 1}\right.$ radiation) were performed by using an imaging plate Guinier camera G670 (Huber), Huber Diffraktionstechnik GmbH, Rimsting, Germany.

\section{Results and Discussion}

\subsection{Phase Transformations in C-H-Si System}

The X-ray diffraction patterns of the synthesized samples are shown in Figure 2. Their analysis shows that the compound transforms into an amorphous matter at a temperature of $560{ }^{\circ} \mathrm{C}$, without mass loss. Decomposition of the material begins at a temperature of about $680{ }^{\circ} \mathrm{C}$, accompanied by sample mass loss of $20 \%$ and the formation of free silicon 
in the amorphous matrix with a changed composition. The formation of nanocrystalline silicon carbide, about $1.6 \mathrm{~nm}$ in size, is observed at $800^{\circ} \mathrm{C}$, while the sample contains an insignificant amount of free silicon in two cubic modifications (ordinary and Kasper's phase). The average crystallite size of $\mathrm{SiC}$ increases intensively to about $150 \mathrm{~nm}$ with the rise in the synthesis temperature up to $1400{ }^{\circ} \mathrm{C}$; however, at higher temperatures, $1600-2000{ }^{\circ} \mathrm{C}$, further growth of the crystals becomes ineffective. The SiC crystallite sizes were estimated by the FWHM of 111 reflections, using the Scherrer formula, and are presented in Table 1, along with the lattice parameters calculated by the Rietveld method, with the use of NIST640c silicon standard. The absence of the strongest 002 line of graphite at 26 degrees in the diffraction patterns of the samples (Figure 2) implies that graphite does not form during the course of the synthesis. The calculated crystallite sizes are in good agreement with the sizes observed in electronic photographs (SEM) (see examples of sample morphology in Figure 1C and Table 1). An example of a crystal size distribution statistical analysis is given in Figures S2 and S3 of Supplementary Materials. Note that because of the small XRD line broadening, the error in determining its value becomes significant if the crystallite size is larger than $150 \mathrm{~nm}$. In accordance with the SEM investigation, the sample obtained by synthesis at $1100{ }^{\circ} \mathrm{C}$ is characterized by agglomeration of the primary particles into 100-200 nm aggregates. At synthesis temperatures of $1250{ }^{\circ} \mathrm{C}$, distinct $\sim 20-30 \mathrm{~nm}$ crystallites are formed (see Figure 1C). At temperatures above $1350-1400{ }^{\circ} \mathrm{C}, 100-500 \mathrm{~nm}$ individual particles are formed, without noticeable size changes at further temperature increases up to $2000^{\circ} \mathrm{C}$.

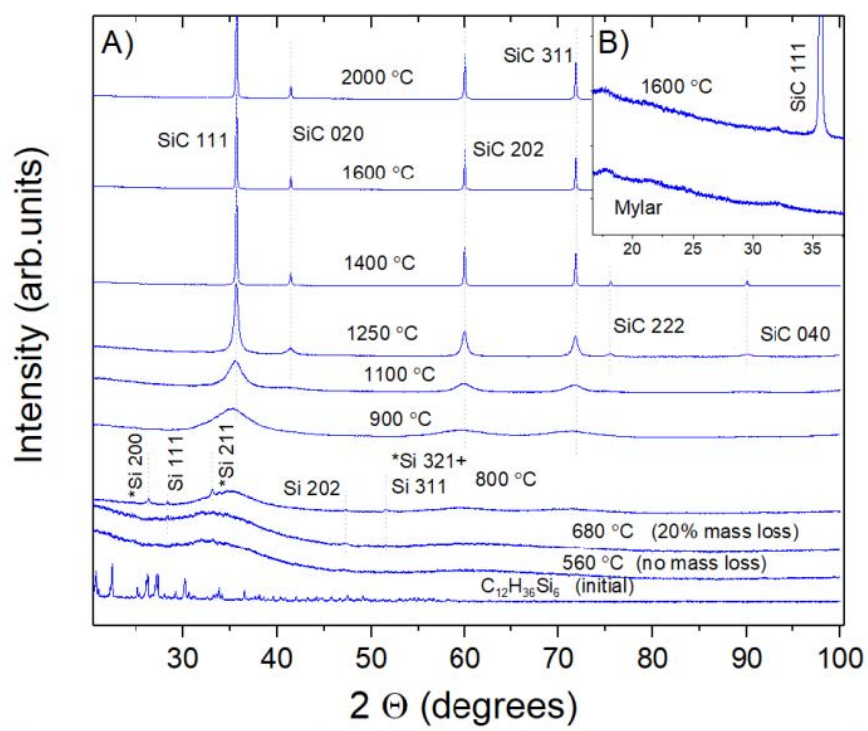

Figure 2. (A) Diffraction patterns of $\mathrm{SiC}$ powders synthesized at different temperatures by pyrolysis of $\mathrm{C}_{12} \mathrm{H}_{36} \mathrm{Si}_{6}$. (B) the XRD pattern background of one sample and Mylar sample holder with no signs of the strongest 002 graphite peak in the patterns.

Table 1. Synthesis temperature (T), lattice parameter (Rietveld analysis), and crystallite size (Scherrer formula) for various $\mathrm{SiC}$ samples. Example of crystal size distribution at $2000{ }^{\circ} \mathrm{C}$ is given in Figure S2 of Supplementary Materials.

\begin{tabular}{cccc}
\hline T, C & a, A (Rietveld Method) & Size (Scherrer Formula), $\mathbf{n m}$ & Measured, $\mathbf{n m}$ \\
\hline 2000 & 4.357 & 200 & $100-500$ \\
1600 & 4.359 & 200 & $100-500$ \\
1400 & 4.359 & 150 & $100-500$ \\
1250 & 4.361 & 22 & $20-50$ \\
1100 & 4.367 & 5 & $<10$ \\
900 & 4.390 & 2 & \\
800 & 4.397 & 1.6 & \\
\hline
\end{tabular}


The results related to the temperature-induced crystal growth of SiC can be interpreted in terms of recrystallization, driven by a decrease in the surface energy of the nanoparticles [34]. After the complete decomposition of the organosilane compound at about $800{ }^{\circ} \mathrm{C}$, there is no longer a source of Si and C feeding crystal growth, except for the nanocrystals themselves.

Similarly to the growth of diamonds under pressure in the C-H growth system [35], $\mathrm{SiC}$ nanocrystals can grow due to the dissolution-precipitation of carbon and silicon in the C-H-Si growth medium, formed during the decomposition of dodecamethylhexasilinane, or due to the coalescence of the nanoparticles [34]. Our experiments show that with a particle size of more than 200-500 nm, a decrease in the surface-to-volume ratio no longer plays a key role as a driving force in the growth of SiC crystals, and crystal growth slows down. It is interesting to note that in experiments based on sintering $\mathrm{SiC}$ nanopowders under pressure, the maximum enlargement of the initial $30 \mathrm{~nm}$ grains up to $120 \mathrm{~nm}$, with the sintering temperature increasing to $1800{ }^{\circ} \mathrm{C}$, is consistent with the concept of slowing the growth when the submicron crystal size is reached [36].

The absence of graphite diffraction peaks in the diffraction patterns of all the synthesized samples convincingly demonstrates that the decomposition of dodecamethylhexasilinane under pressure proceeds with the predominant formation of hydrocarbons, and without molecular hydrogen and free carbon. Otherwise, we would observe the noticeable formation of graphite or diamond mixed with $\mathrm{SiC}$.

\subsection{Optical Properties}

\subsubsection{Raman Spectra and IR Transmission}

When studying optical properties, the main emphasis was placed on powders with an average particle size of $\sim 100-300 \mathrm{~nm}$, obtained at temperatures of $1350-2000{ }^{\circ} \mathrm{C}$. This is due to the fact that the role of inhomogeneous broadening in optical spectra is of secondary importance for such powders, which allows a sequential (joint) analysis of IR transmission, Raman scattering, and luminescence spectra. In addition, at temperatures higher than $1300{ }^{\circ} \mathrm{C}, \mathrm{SiC}$ particles do not show the tendency to agglomerate; therefore, they may be regarded as a more perspective material for IR photonics [31].

Figure 3A illustrates a typical IR transmission spectrum of SiC powder, recorded at room temperature, using a Bruker Optics IFS 66V IR Fourier-transform spectrometer (spectral resolution: $4 \mathrm{~cm}^{-1}$ ). To measure the transmission spectra, tablets containing $200 \mathrm{mg}$ of pure $\mathrm{KBr}$ and $4 \mathrm{mg}$ of $\mathrm{SiC}$ were prepared. The spectrum contains a dip characteristic of $\mathrm{SiC}$, which corresponds to the region located between the $\mathrm{LO}$ and $\mathrm{TO}$ resonances. In the high-frequency region, absorption peaks associated with second-order processes are clearly recorded [37]. In addition, on the high-frequency part of the strong lattice reflection region, weak dips are observed in their spectral position, close to the frequency of the longitudinal optical (LO) phonons. Those dips can be attributed to the surface plasmon polaritons that are characteristic of doped (containing free carriers) 3C SiC particles [29].

The Raman spectra were measured using the following two devices: a portable EnSpectr R532 Raman spectrometer coupled to an Olympus S41 optical microscope, and a laboratory Raman spectrograph equipped with a cooled CCD detector. In the first case, a laser beam (wavelength $\lambda=532 \mathrm{~nm}$ ), passing through an objective lens, was focused onto a sample placed on an adjustable stage. The Raman signal falling within the range of Stokes shifts (150-4000 $\mathrm{cm}^{-1}$ ) was recorded by a CCD matrix in the backscattering geometry with a $4 \mathrm{~cm}^{-1}$ spectral resolution. The typical excitation laser power was $1-5 \mathrm{~mW}$, and the spot size, determined by the selected objective lens, was varied from 2 to $10 \mu \mathrm{m}$. As for the laboratory spectrograph, single-frequency lasers, operating at $472 \mathrm{~nm}, 532 \mathrm{~nm}$, and $632 \mathrm{~nm}$, were used as excitation sources. The excitation spot diameter on the sample was $\sim 2 \mu \mathrm{m}$. The spectral resolution was $1 \mathrm{~cm}^{-1}$. The laboratory spectrograph also enabled measurements at low temperatures. Different wavelengths were required to separate the Raman and luminescence signals. The characteristic form of the Raman spectra of SiC powders did not practically depend on the selected excitation wavelength. 

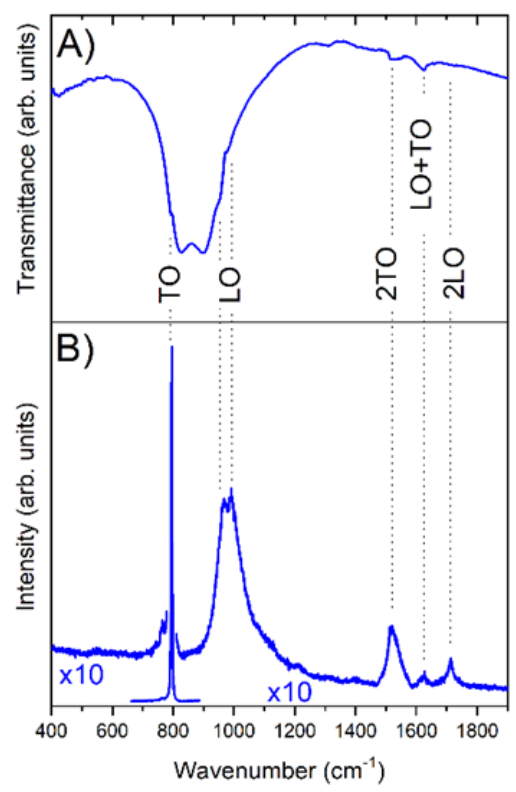
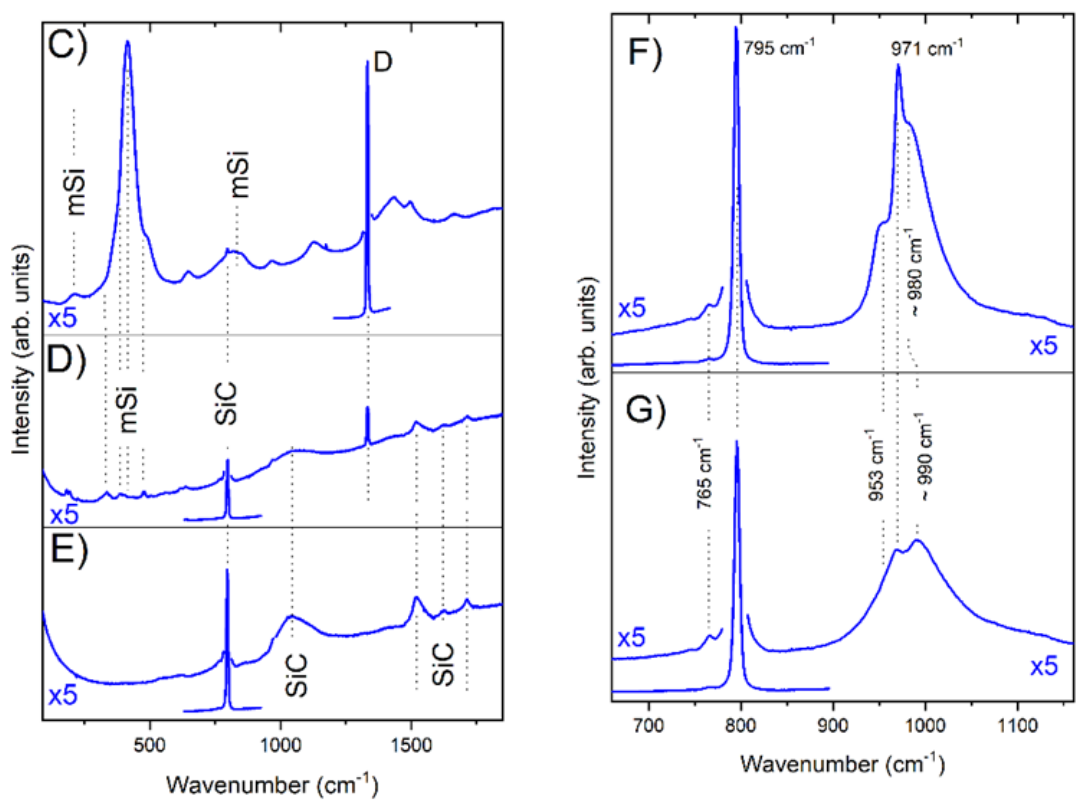

Figure 3. (A) IR transmission spectra of SiC crystals near lattice resonances. (B) Raman spectra upon excitation of the crystal by radiation with a wavelength of $632 \mathrm{~nm}$. (C-E) Raman spectra for the following individual particles found in the sample synthesized in Ti capsule at $1600{ }^{\circ} \mathrm{C}$ : (C) a particle, mainly consisting of a diamond phase and metastable silicon; (D) a particle comprising $\mathrm{SiC}$, a diamond phase, and metastable silicon; (E) silicon carbide crystal. Raman spectra for submicron particles, synthesized at $1350{ }^{\circ} \mathbf{C}$, before $(\mathbf{F})$ and after annealing $(\mathbf{G})$ in the region corresponding to the first-order processes with participation of optical phonons. The spectra in Panel $(\mathbf{C}-\mathbf{G})$ were recorded using $532 \mathrm{~nm}$ excitation.

Figure 3B illustrates a typical Raman spectrum in synthesized micropowders. The most intense peaks are related to the first-order processes, involving transverse optical (TO) and longitudinal optical (LO) phonons corresponding to the $\Gamma$ point of the Brillouin zone [38]. The spectral position of the peak corresponding to the TO phonon $\left(\sim 795 \mathrm{~cm}^{-1}\right)$ indicates that the crystals studied belong to the $3 \mathrm{C}$ polytype. This conclusion is consistent with the results of the X-ray structural analysis. In the region of the LO phonons, a fine structure is recorded, which is shifted to longer wavelengths with respect to the line characteristic of the $\mathrm{LO}(\Gamma)$ phonons of $3 \mathrm{C} \mathrm{SiC}$. This behavior, which indicates the formation of mixed phonon-plasmon modes, independently confirms the presence of a noticeable concentration of free carriers in the synthesized crystals [39].

In the $1300-1800 \mathrm{~cm}^{-1}$ range, peaks at $1512 \mathrm{~cm}^{-1}, 1626 \mathrm{~cm}^{-1}$, and $1712 \mathrm{~cm}^{-1}$ are recorded, which correspond to the second-order Raman processes [40]. The spectral position of these peaks is consistent with the results of the IR transmission spectra measurements in Figure 3A. The lowest frequency peak (2TO) arises due to the scattering of two transverse optical phonons related to the $\mathrm{L}$ point of the $\mathrm{SiC}$ Brillouin zone. The middle peak $(\mathrm{LO}+\mathrm{TO})$ is the least intense; it is not an overtone of the optical phonon modes, and it corresponds to a combination of phonons of different branches. The high-frequency peak (2LO) is the result of the scattering of two transverse optical phonons, with quasimomenta near the $\mathrm{M}$ point of the Brillouin zone [41].

Figure 3C-E illustrate a typical view of the Raman spectra of the micropowders obtained in the Ti capsule at $1600{ }^{\circ} \mathrm{C}$. If XRD characterizes the sample bulk as a single SiC $3 C$ phase (see Figure 2), micro-Raman investigations allow us to examine local variations in the sample composition. The Raman spectrum in Figure $3 C$ shows the formation of diamond (D) [42] and metastable silicon ( $\mathrm{mSi}$ ) as impurity phases [43]. Figure 3D illustrates the presence of diamond and various phases of amorphous silicon, along with silicon carbide in the analyzing spot. Finally, Figure 3E illustrates the spectrum of silicon carbide microcrystals, free of the diamond (graphite) phase and metastable silicon phases. In 
general, the data presented in Figure 2 allow possible by-products of the synthesis of silicon carbide to be traced from dodecamethylhexasilinane.

To study the structural features of the synthesized $\mathrm{SiC}$, a series of experiments were carried out to establish the effect of annealing in a vacuum on the Raman spectra. Examples of Raman spectra, before and after annealing in the region corresponding to the firstorder scattering by optical phonons, are illustrated in Figure 3F,G. As can be seen from the figures, the spectrum in the TO phonon region does not change after annealing, and exhibits an intense peak in the region of $795 \mathrm{~cm}^{-1}$, which is typical for the $3 \mathrm{C}$ polytype. Nevertheless, in the $765 \mathrm{~cm}^{-1}$ region, a weak structure is recorded, the intensity of which is $\sim 300-500$ times less than the main (TO) peak intensity. Before annealing, a doublet structure is observed in the region of scattering by the LO phonons. The high-frequency $\left(\sim 990 \mathrm{~cm}^{-1}\right)$ component of this structure corresponds to the mixed phonon-plasmon modes in doped $3 \mathrm{C} \mathrm{SiC}$, and the low-frequency component is located a few inverse centimeters below the $\mathrm{LO}(\Gamma)$ resonance in the undoped $3 \mathrm{C} \mathrm{SiC}$. This fine structure is not associated with (possible) luminescent centers, and is retained in the Raman spectra of $100 \mathrm{~nm}$ individual crystals (see Figure S4 of Supplementary Materials). Similar behavior of the Raman spectra in the LO phonons region is observed in the case of nano- or submicron particles of $3 \mathrm{C}$ silicon carbide, in which a heavily doped region (core) is surrounded by a SiC layer (shell) depleted in carriers [29]. In this case, the formation of phonon-plasmon coupled modes, in combination with size effects, can explain the low-frequency and high-frequency components near LO resonance [29].

It should be noted that in the crystals synthesized at $1100{ }^{\circ} \mathrm{C}$, there is no fine structure in the Raman spectrum near LO phonon resonance (a relatively narrow line, with a maximum at $970 \mathrm{~cm}^{-1}$, is observed). This means that no regions with a high carrier concentration are formed in $\sim 5 \mathrm{~nm}$ particles. Therefore, one can argue that the region with a high carrier concentration (core) is formed in the particle center if its radius exceeds the depth of the carrier-depleted layer near the surface (shell). This situation can apparently be observed for relatively large particles synthesized at $1350^{\circ} \mathrm{C}$ and above.

After annealing, the fine structure described above transforms into an asymmetric line with a maximum at $971 \mathrm{~cm}^{-1}$, which coincides with the frequencies of the $\mathrm{LO}(\Gamma)$ phonons in undoped $3 \mathrm{C} \mathrm{SiC} \mathrm{[38].} \mathrm{Thus,} \mathrm{the} \mathrm{tuning} \mathrm{of} \mathrm{the} \mathrm{high-frequency} \mathrm{LO} \mathrm{peak} \mathrm{component}$ in Figure $3 \mathrm{~F}$ corresponds to the transition from a mixed phonon-plasmon mode in the $3 \mathrm{C}$-doped $\mathrm{SiC}$, to scattering by conventional $\mathrm{LO}(\Gamma)$ phonons in the pure $3 \mathrm{C} \mathrm{SiC} \mathrm{[39].} \mathrm{Nev-}$ ertheless, the long-wavelength structure observed in the spectra of the annealed crystals in the $\sim 980 \mathrm{~cm}^{-1}$ region indicates the retention of regions in which the carrier concentration remains sufficiently high. The spectral position of the mixed phonon-plasmon mode enables the free carrier concentration to be estimated using the results of [29] (see Figures S5-S7 of Supplementary Materials). For the core of the as-grown particles, this concentration is at the level of 2-3 $\times 10^{18} \mathrm{~cm}^{-3}$, and drops to $\sim 10^{18} \mathrm{~cm}^{-3}$ after annealing. It should be noted that for submicron-sized crystals, the mixed phonon-plasmon mode position depends on both the carrier concentration and the shape/internal structure/environment of the crystal. Therefore, the values obtained should be interpreted as estimates.

The presence of less intense, low-frequency components of the TO and LO phonon peaks could also be attributed to the presence of the $6 \mathrm{H}$ polytype in microcrystals. Nevertheless, with such an interpretation, one should expect comparable (and not differing by an order of magnitude) intensities for the TO and LO components, in the region of $\sim 765 \mathrm{~cm}^{-1}$ and $\sim 955 \mathrm{~cm}^{-1}$, respectively [38]. In addition, in the presence of other polytypes besides 3C, the Raman spectra should contain peaks in the region of $140-270 \mathrm{~cm}^{-1}$, which correspond to scattering by acoustic phonons [39]. In the studied crystals, those peaks were not observed. It should be noted that low-frequency shifts of the TO component can appear in the presence of stacking faults [44]. 


\subsubsection{Low-Temperature Photoluminescence}

To assess the impurity-defect composition and determine the main reason for the appearance of free carriers, a series of experiments were carried out to measure the lowtemperature photoluminescence spectra of the synthesized crystals. Figure 4 illustrates typical examples of such spectra, recorded for the original (panels $\mathrm{A}, \mathrm{B}$ ) and annealed crystals (panel C). Panel A in Figure 4 corresponds to the synthesis conditions under which the formation of side phases is not observed. Panel B corresponds to the situation in which metastable silicon and diamond are formed, along with SiC powders. In this case, the presence of diamond leads to the appearance of a narrow emission line of SiV centers in the PL spectra [45].
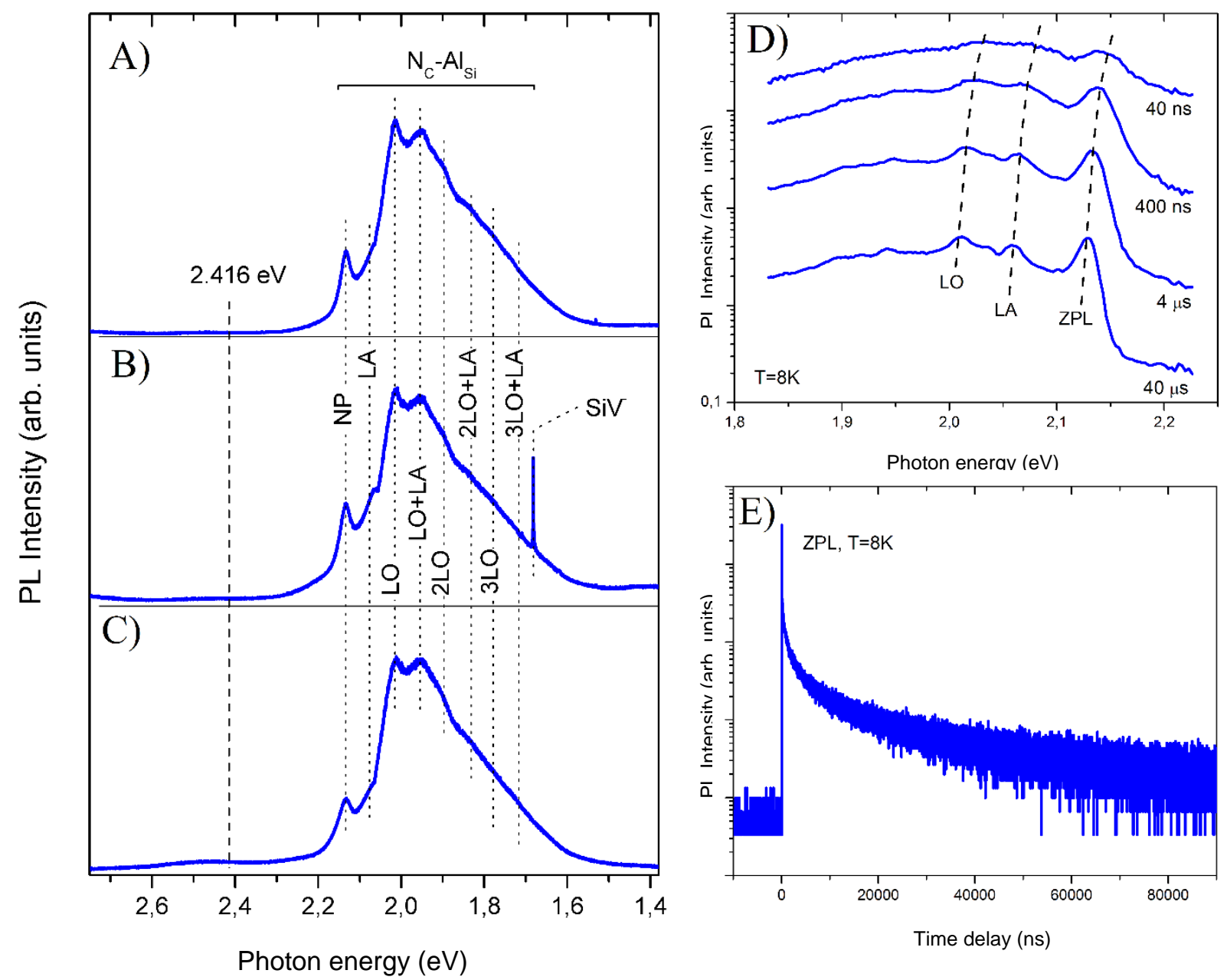

Figure 4. Examples of low-temperature (5K) photoluminescence spectra recorded for the as-grown (panels A,B) and annealed crystals (panel C). Panel (A) corresponds to the synthesis conditions in which the formation of side phases was not detected. Panel (B) corresponds to the situation in which metastable silicon and diamond were formed along with SiC during the synthesis. The dotted line marks the position of the fundamental absorption edge of 3C SiC. (Panels D,E) show time-resolved PL spectra and PL kinetics corresponding to the steady-state spectrum in Panel (A).

Except for the $\mathrm{SiV}$ emission line in all the spectra in Figure 4A-C, a similar structure is observed. This structure consists of a zero-phonon line (ZPL) near $2.13 \mathrm{eV}$, and its phonon replicas, with the participation of LO and LA phonons, with a quasimomentum located at the edge of the SiC Brillouin zone [46]. This structure was unambiguously assigned to the emission of the donor-acceptor pairs, with the nitrogen on the carbon sublattice $\left(\mathrm{N}_{\mathrm{C}}\right)$ and the aluminum on the silicon sublattice $\left(\mathrm{Al}_{\mathrm{Si}}\right)$ in the $3 \mathrm{C}$ polytype [47]. In our experiments, the assignment of this line to the donor-acceptor pairs was confirmed by measurements of the luminescence kinetics, as well as time-resolved luminescence spectra. In particular, ZPL 
reveals the long-wavelength shift of the emission lines with an increasing time delay and non-exponential intensity decay (see Figure 4D,E). This behavior, being a unique feature of donor-acceptor pairs, is governed by the spread of the distances between acceptors and donors [47].

On the one hand, the high intensity of the emission band of donor-acceptor pairs, in comparison with the excitation emission near the fundamental absorption edge of the 3C SiC (marked in Figure 4 with a dashed line), confirms the noticeable concentration of the corresponding point defects. On the other hand, the absence of any additional defect-related bands indicates that $\mathrm{N}_{C}$ and $\mathrm{Al}_{\mathrm{Si}}$ are dominant types of shallow defects in the synthesized crystals. The nitrogen on the carbon sublattice in 3C SiC forms a donor center, the ground state energy of which is $53 \mathrm{MeV}$. At room temperature, this value is comparable to thermal energy; therefore, a significant part of the donor center turns out to be ionized. At the same time, the ground state energy for the $\mathrm{Al}_{\mathrm{Si}}$ acceptor is $257 \mathrm{MeV}$, which is sufficient to significantly suppress their ionization at room temperature. Thus, it can be argued that the main reason for the appearance of free carriers in synthesized crystals is the ionization of the $\mathrm{N}_{\mathrm{C}}$ donors. It should be noted that the electron concentrations of $\sim 1-3 \times 10^{18} \mathrm{~cm}^{-3}$, estimated above, exclude the reliable registration of donor impurities by the EDX method.

\section{Conclusions}

Thus, the HTHP synthesis of $3 \mathrm{C}$ silicon carbide powders from dodecamethylhexasilinane was carried out. It has been shown that by increasing the synthesis temperature from $800{ }^{\circ} \mathrm{C}$ to $1400{ }^{\circ} \mathrm{C}$, it is possible to monotonically regulate the average crystallite size from $\sim 2 \mathrm{~nm}$ to $\sim 500 \mathrm{~nm}$. At higher temperatures, further enlargement of the crystals is impeded, which is consistent with the recrystallization mechanism driven by a decrease in the surface energy of the particles. The main point defects in the synthesized crystals are aluminum impurities on the silicon sublattice $\mathrm{Al}_{\mathrm{Si}}$ (acceptor) and nitrogen impurities on the carbon sublattice $\mathrm{N}_{C}$ (donor), but the concentrations of $\mathrm{Al}$ and $\mathrm{N}_{C}$ are outside the EDX sensitivity range. The Raman spectra, as well as the IR absorption spectra, indicate that the submicron particles obtained at $1350-2000{ }^{\circ} \mathrm{C}$ contain regions with both significant carrier concentration and depletion. Apparently, an increase of $\sim 2-3 \cdot 10^{18} \mathrm{~cm}^{-3}$ in the concentration of carriers is characteristic of the core, surrounded by a depleted SiC layer (shell). We attribute the appearance of a noticeable concentration of free carriers to the relatively shallow $\mathrm{N}_{\mathrm{C}}$ donor formation. When the synthesis conditions deviate from the optimum, the growth of $3 \mathrm{C} \mathrm{SiC} \mathrm{competes} \mathrm{with} \mathrm{the} \mathrm{formation} \mathrm{of} \mathrm{diamond} \mathrm{and} \mathrm{metastable} \mathrm{silicon.}$

It is shown that the annealing of the $\mathrm{SiC}$ powders, obtained in a vacuum at $\sim 1500{ }^{\circ} \mathrm{C}$, leads to a noticeable (at least several times) decrease in the concentration of free carriers, while keeping $\mathrm{Al}_{\mathrm{Si}}$ and $\mathrm{N}_{\mathrm{C}}$ as the dominant point defects.

In general, the results obtained indicate that the developed synthesis technology, in combination with subsequent annealing in the vacuum, enables control over not only the size of the 3C SiC crystals, but also the properties of the localized phonon-plasmon resonance within the $3 \mathrm{C} \mathrm{SiC} \mathrm{crystals.} \mathrm{The} \mathrm{latter} \mathrm{feature} \mathrm{may} \mathrm{be} \mathrm{of} \mathrm{interest} \mathrm{for} \mathrm{the} \mathrm{creation}$ of hybrid systems with near-field resonant coupling in the mid-IR range.

Supplementary Materials: The following are available online at https:/ / www.mdpi.com/article/10 $.3390 /$ nano11113111/s1, Figure S1: X-ray characteristic spectrum of a sample obtained at $2000{ }^{\circ} \mathrm{C}$; Figure S2: Statistical analysis of one of the characteristic samples synthesized at $2000{ }^{\circ} \mathrm{C}$; Figure S3: The SEM photo of the sample synthesized at $2000{ }^{\circ} \mathrm{C}$; Figure S4: Raman spectra of individual SiC particles obtained with different laser excitation wavelengths; Figure S5: Examples of calculated Raman spectra for "core-shell" particles depending on the plasma frequency; Figure S6: Calculated Raman spectra for core-shell particles depending on $\mathrm{R}_{\mathrm{cs}}$; Figure S7: Calculated Raman spectra for core-shell particles as a function of $\gamma_{\mathrm{e}}$.

Author Contributions: Conceptualization, E.A.E. and V.S.K.; software, D.A.Z.; investigation, E.A.E., D.A.L., R.A.K., L.N.G., A.V.K. and D.F.A.; resources, E.A.E.; data curation, M.V.K. and D.A.L.; 
writing—original draft preparation, all authors.; writing—review and editing, E.A.E., V.S.K., D.A.Z. and S.N.N. All authors have read and agreed to the published version of the manuscript.

Funding: This work is supported by the Russian Science Foundation (Grant No. 19-12-00407, Sections 2 and 3.1) and Russian Foundation of basic research (Grant No. 18-29-20122, Section 3.2).

Acknowledgments: We thank Zibrov I.P. for technical assistance in the X-ray diffraction experiments.

Conflicts of Interest: The authors declare no conflict of interest.

\section{References}

1. Anggara, B.S.; Fahdiran, R.; Marpaung, M.A.; Soegijono, B. Silicon Carbide (SiC) Effect on Mechanical Properties and Corrosion Rates on Composite $\mathrm{Al} / \mathrm{SiC}$ and $\mathrm{Al}-\mathrm{Cu} / \mathrm{SiC}$; American Institute of Physics Inc.: College Park, MD, USA, 2019. [CrossRef]

2. Davidsson, J.; Ivády, V.; Armiento, R.; Ohshima, T.; Son, N.T.; Gali, A.; Abrikosov, I.A. Erratum: Identification of divacancy and silicon vacancy qubits in 6H-SiC. Appl. Phys. Lett. 2020, 116, 059901. [CrossRef]

3. Zhu, Y.; Kovos, B.; Onizhuk, M.; Awschalom, D.; Gal, G.L. Theoretical and experimental study of the nitrogen-vacancy center in 4H-SiC. Phys. Rev. Mater. 2021, 5, 074602. [CrossRef]

4. Su, J.; Yang, Y.; Ren, J.; Guo, P. Study on magnetic properties of Fe-doped 3C-SiC nanowires. J. Cryst. Growth 2020, 532, 125412. [CrossRef]

5. Yu, Y.; Liyan, L.; Guifu, D.; Ting, C. SiC nanowire-based SU-8 with enhanced mechanical properties for MEMS structural layer design. Nanotechnol. Precis. Eng. 2019, 2,169-176. [CrossRef]

6. Mi, Y.; Chen, Y.; Zheng, Z.; Qiao, N.; Liang, Y. New discoveries in the growth of SiC whiskers derived from hydrogen silicone oil. J. Cryst. Growth 2020, 543, 125711. [CrossRef]

7. Károly, Z.; Mohai, I.; Klébert, S.; Keszler, A.; Sajó, I.E.; Szépvölgyi, J. Synthesis of SiC powder by RF plasma technique. Powder Technol. 2011, 214, 300-305. [CrossRef]

8. Wu, R.; Zhou, K.; Yue, C.Y.; Wei, J.; Pan, Y. Recent progress in synthesis, properties and potential applications of SiC nanomaterials. Prog. Mater. Sci. 2015, 72, 1-60. [CrossRef]

9. Dai, D.; Zhang, N.; Zhang, W.; Fan, J. Highly bright tunable blue-violet photoluminescence in SiC nanocrystal-sodium dodecyl sulfonate crosslinked network. Nanoscale 2012, 4, 3044-3046. [CrossRef] [PubMed]

10. Cooper, O.; Wang, B.; Brown, C.L.; Tiralongo, J.; Iacopi, F. Toward Label-Free Biosensing with Silicon Carbide: A Review. IEEE Access 2016, 4, 477-497. [CrossRef]

11. Wright, N.G.; Horsfall, A.B. SiC sensors: A review. J. Phys. D Appl. Phys. 2007, 40, 6345-6354. [CrossRef]

12. Chaira, D.; Mishra, B.K.; Sangal, S. Synthesis and characterization of silicon carbide by reaction milling in a dual-drive planetary mill. Mater. Sci. Eng. A 2007, 460-461, 111-120. [CrossRef]

13. Real, C.; Alcala, D.; Criado, J.M. Synthesis of silicon carbide whiskers from carbothermal reduction of silica gel by means of the constant rate thermal analysis (CRTA) method. Solid State Ion. 1997, 95, 29-32. [CrossRef]

14. Pan, S.; Zhang, J.; Yang, Y.; Song, G. Effect of process parameters on the production of nanocrystalline silicon carbide from water glass. Ceram. Int. 2008, 34, 391-395. [CrossRef]

15. Narciso-Romero, F.J.; Rodriguez-Reinoso, F.; Diez, M.A. Influence of the carbon material on the synthesis of silicon carbide. Carbon 1999, 37, 1771-1778. [CrossRef]

16. Yang, Y.; Lin, Z.M.; Li, J.T. Synthesis of SiC by silicon and carbon combustion in air. J. Eur. Ceram. Soc. 2009, 29, 175-180. [CrossRef]

17. Ebadzadeh, T.; Marzban-Rad, E. Microwave hybrid synthesis of silicon carbide nanopowders. Mater. Charact. 2009, 60, 69-72. [CrossRef]

18. Narisawa, M.; Shimoda, M.; Okamura, K.; Sugimoto, M. Reaction Mechanism of the Pyrolysis of Polycarbosilane and Polysilazane as Ceramic Precursors. Bull. Chem. Soc. Jpn. 1995, 68, 1098-1104. [CrossRef]

19. Čerović, L.; Milonjić, S.K.; Zec, S.P. A comparison of sol-gel derived silicon carbide powders from saccharose and activated carbon. Ceram. Int. 1995, 21, 271-276. [CrossRef]

20. Cao, L.Z.; Jiang, H.; Song, H.; Liu, X.; Guo, W.G.; Yu, S.Z.; Li, Z.M.; Miao, G.Q. SiC/SiO 2 core-shell nanowires with different shapes: Synthesis and field emission properties. Solid State Commun. 2010, 150, 794-798. [CrossRef]

21. Schaaf, P.; Kahle, M.; Carpene, E. Reactive laser synthesis of carbides and nitrides. Appl. Surf. Sci. 2005, 247, 607-615. [CrossRef]

22. Rai, P.; Park, J.S.; Park, G.G.; Lee, W.M.; Yu, Y.T.; Kang, S.K.; Moon, S.Y.; Hong, B.G. Influence of carbon precursors on thermal plasma assisted synthesis of SiC nanoparticles. Adv. Powder Technol. 2014, 25, 640-646. [CrossRef]

23. Sasaki, Y.; Nishina, Y.; Sato, M.; Okamura, K. Raman study of SiC fibres made from polycarbosilane. J. Mater. Sci. 1987, 22, 443-448. [CrossRef]

24. Ko, S.M.; Koo, S.M.; Cho, W.S.; Hwnag, K.T.; Kim, J.H. Synthesis of SiC nano-powder from organic precursors using RF inductively coupled thermal plasma. Ceram. Int. 2012, 38, 1959-1963. [CrossRef]

25. Voronin, G.A.; Pantea, C.; Zerda, T.W.; Ejsmont, K. Oriented growth of $\beta$-SiC on diamond crystals at high pressure. J. Appl. Phys. 2001, 90, 5933-5935. [CrossRef] 
26. Ekimov, E.A.; Sadykov, R.A.; Gierlotka, S. A High-Pressure Cell for High-Temperature Experiments in a Toroid-Type Chamber. Instrum. Exp. Tech. 2004, 47, 276-278. [CrossRef]

27. Zhong, Y.; Malagari, S.D.; Hamilton, T.; Wasserman, D.; Malagari, D. Review of Mid-Infrared Plasmonic Materials. 2015. Available online: http:/ / nanophotonics.spiedigitallibrary.org/ (accessed on 5 November 2015).

28. Bohren, C.F.; Wickramasinghe, N.C. On the Computation of Optical Properties of Heterogeneous Grains. Astrophys. Space Sci. 1977, 50, 461-472. [CrossRef]

29. Sasaki, Y.; Nishina, Y.; Sato, M.; Qkamura, K. Optical-phonon states of SiC small particles studied by Raman scattering and infrared absorption. Phys. Rev. B 1989, 40, 1762. [CrossRef]

30. Feng, K.; Streyer, W.; Islam, S.M.; Verma, J.; Jena, D.; Wasserman, D.; Hoffman, A.J. Localized surface phonon polariton resonances in polar gallium nitride. Appl. Phys. Lett. 2015, 107, 081108. [CrossRef]

31. Krivobok, V.S.; Kondorskiy, A.D.; Pashkeev, D.A.; Ekimov, E.A.; Shabrin, A.D.; Litvinov, D.A.; Grigoreva, L.N.; Kolosov, S.A.; Chernopitsskii, M.A.; Klekovkin, A.V.; et al. A Hybrid Mid-IR Photodetector Based on Semiconductor Quantum Wells. Tech. Phys. Lett. 2021, 47, 402-405. [CrossRef]

32. Yang, B.; Wu, T.; Yang, Y.; Zhang, X. Effects of charges on the localized surface phonon polaritons in dielectric nanoparticles. J. Opt. Soc. Am. B 2017, 34, 1303. [CrossRef]

33. Kondrina, K.M.; Kudryavtsev, O.S.; Vlasov, I.I.; Khmelnitskiy, R.A.; Ekimov, E.A. High-pressure synthesis of microdiamonds from polyethylene terephthalate. Diam. Relat. Mater. 2018, 83, 190-195. [CrossRef]

34. Leite, E.R.; Ribeiro, C. Crystallization and Growth of Colloidal Nanocrystals; Springer Science \& Business Media: Berlin/Heidelberg, Germany, 2012. [CrossRef]

35. Ekimov, E.A.; Kondrin, M.V.; Krivobok, V.S.; Khomich, A.A.; Vlasov, I.I.; Khmelnitskiy, R.A.; Iwasaki, T.; Hatano, M. Effect of $\mathrm{Si}, \mathrm{Ge}$ and Sn dopant elements on structure and photoluminescence of nano- and microdiamonds synthesized from organic compounds. Diam. Relat. Mater. 2019, 93, 75-83. [CrossRef]

36. Gubicza, J.; Nauyoks, S.; Balogh, L.; Labar, J.; Zerda, T.W.; Ungár, T. Influence of sintering temperature and pressure on crystallite size and lattice defect structure in nanocrystalline SiC. J. Mater. Res. 2007, 22, 1314-1321. [CrossRef]

37. Hofmeister, A.M.; Pitman, K.M.; Goncharov, A.F.; Speck, A.K. Optical constants of silicon carbide for astrophysical applications. II. Extending optical functions from infrared to ultraviolet using single-crystal absorption spectra. Astrophys. J. 2009, 696, 1502-1516. [CrossRef]

38. Aksyanov, I.G.; Kompan, M.E.; Kul'kova, I.V. Raman scattering in mosaic silicon carbide films. Phys. Solid State 2010, 52, 1850-1854. [CrossRef]

39. Yugami, H.; Nakashima, S.; Mitsuishi, A.; Uemoto, A.; Shigeta, M.; Furukawa, K.; Suzuki, A.; Nakajima, S. Characterization of the free-carrier concentrations in doped $\beta$-SiC crystals by Raman scattering. J. Appl. Phys. 1987, 61, 354-358. [CrossRef]

40. Rohmfeld, S.; Hundhausen, M.; Ley, L. Raman scattering in polycrystalline 3C-SiC: Influence of stacking faults. Physical Review B 1998, 58, 9858. [CrossRef]

41. Ekimov, E.A.; Lyapin, S.G.; Grigoriev, Y.v.; Zibrov, I.P.; Kondrina, K.M. Size-controllable synthesis of ultrasmall diamonds from halogenated adamantanes at high static pressure. Carbon 2019, 150, 436-438. [CrossRef]

42. Xu, Z.; He, Z.; Song, Y.; Fu, X.; Rommel, M.; Luo, X.; Hartmaier, A.; Zhang, J.; Fang, F. Topic review: Application of raman spectroscopy characterization in micro/nano-machining. Micromachines 2018, 9, 361. [CrossRef]

43. Ekimov, E.A.; Sherin, P.S.; Krivobok, V.S.; Lyapin, S.G.; Gavva, V.A.; Kondrin, M.V. Photoluminescence excitation study of split-vacancy centers in diamond. Phys. Rev. B 2018, 97, 045206. [CrossRef]

44. Kuwabara, H.; Yamada, S. Free-to-Bound Transition in beta-SiC Doped with Boron. Phys. Stat. Sol. 1975, 30, 739. [CrossRef]

45. Bishop, S.G.; Freitas, J.A. Photoluminescence characterization of cubic SiC grown by chemical vapor deposition on Si substrates. J. Cryst. Growth 1990, 106, 38-46. [CrossRef]

46. Borowicz, P.; Gutt, T.; Małachowski, T.; Łatek, M. Structural investigation of silicon carbide with micro-raman spectroscopy. In Proceedings of the 2009 MIXDES-16th International Conference Mixed Design of Integrated Circuits \& Systems, Lodz, Poland, 25-27 June 2009.

47. Bai, S.; Ke, Y.; Shishkin, Y.; Shigiltchoff, O.; Devaty, R.P.; Choyke, W.J.; Strauch, D.; Stojetz, B.; Dorner, B.; Hobgood, D.; et al. Four current examples of characterization of silicon carbide. Mater. Res. Soc. Symp.-Proc. 2002, 742, 151-162. [CrossRef] 